\title{
THE EVOLUTION AND BREAKDOWN OF S-ALLELE SYSTEMS
}

\author{
D. CHARLESWORTH and B. CHARLESWORTH \\ School of Biological Sciences, University of Sussex, Brighton BNI $9 Q G$, England
}

Received 13.iii.79

\section{SUMMARY}

\begin{abstract}
We have examined a model proposed by East (1929) for the evolution of gametophytic self-incompatibility allele systems, starting from populations with a self-fertility allele. The original self-fertility allele is not eliminated from the population when three active $S$ alleles have been incorporated, but self-fertility alleles can coexist with $S$ alleles. In order to examine this coexistence more fully, we studied the invasion of self-incompatible populations containing various numbers of $S$ alleles (all assumed to be equally frequent) by three possible types of self-compatibility factors that could arise by mutation at the $S$ locus. We find that there is always some critical number of active $S$ alleles that ensures the elimination of mutant alleles with no activity in pollen; this number depends on the inbreeding depression. Alleles abolishing the stigma activity can spread, irrespective of how many active alleles are present, provided the inbreeding depression is small enough. Some of the biological implications of these results are discussed.
\end{abstract}

\section{INTRODUGTION}

HомомоRPHIC self-incompatibility has been found in a very wide range of flowering plant species, in many different orders (East, 1940), and the genetic basis has been established in a small proportion. With the exception of members of the Cruciferae (Bateman, 1955; Sampson, 1957) and Compositae (Gerstel, 1950; Hughes and Babcock, 1950; Crowe, 1954; Sampson, 1964; Lloyd, 1967) which have a sporophytic system, the pollen reaction type is determined gametophytically and depends on the alleles at a single $S$ locus (East and Mangelsdorf, 1925), or at more than one locus (Lundqvist, 1954, 1975; Hayman, 1956). The present paper is concerned with single-locus gametophytic systems. No satisfactory account of the evolution of this system is available. Many (e.g. Mather, 1943, p. 229) have laid stress on the fact that three or more alleles are necessary if the population is to be perpetuated, and it has been suggested that this presents a nearly insuperable barrier to the evolution of self-incompatibility systems of this sort from an initially self-compatible state (Mather, 1944). This has led to the conclusion that self-incompatibility arose only once in the evolution of the angiosperms (Whitehouse, 1950). The distribution of self-incompatibility in the angiosperms does not readily fit such a view (see, for example, Brewbaker, 1959), since no cases of incompatibility have been found in several supposedly primitive orders. Moreover, the clear differences in details of the incompatibility systems between families, in contrast to within-family homogeneity (see Brewbaker, 1957; Heslop-Harrison, Heslop-Harrison and Barber, 1975) appears to be at variance with a monophyletic origin. 
East (1929, p. 360) was aware of the difficulty that three alleles are necessary for the propagation of a population with a gametophytic $S$-allele system, and suggested that this does not present a problem for the evolution of such systems if the population initially contains a self-fertility allele which, for example, enables pollen carrying it to fertilise any genotype. Various possible types of self-fertility allele can be imagined. We shall discuss these below. East (1929) also suggested that "the assurance of cross-fertilisation, with the attendant vigour of heterosis" is the most likely advantage for such mutations. Mather (1943) criticised this view because, since we cannot believe that "the advantage of outbreeding arises suddenly, at the same time as the $S_{1}$ mutation occurs . . . the self-compatible species must have persisted for some time while waiting, so to speak, for mutations converting it into the fitter incompatible type. This seems highly improbable". To us, this does not appear as unlikely as Mather believes. If the nature of the mutation required to produce incompatibility is a physiologically unlikely one (for example, an extremely complex change), such a mutation might well be potentially favoured, yet require much time before one could be expected to become incorporated into a population. We have therefore investigated a model based on East's original theory of the evolution of a self-incompatibility system, assuming that the starting population is homogeneous for a self-fertility allele, which will be denoted by $S_{f}$. This allele is assumed to be an inactive incompatibility allele, such that $S_{f}$ pollen can fertilise any genotype $S_{i} S_{j}$, including genotypes carrying $S_{f}$, and $S_{f} S_{f}$ plants can be fertilised by any pollen type. Such $S_{f}$ alleles have been found in self-fertile plant species, such as Nicotiana langsdorffi (East, 1919, 1932), and in self-fertile strains or individuals in otherwise incompatible species (Attwood, 1942, 1945; Williams and Williams, 1947; Lundqvist, 1968; Takehashi, 1973). Some other possible types of initial allele are also studied.

Another problem that can be studied using similar methods is the breakdown of incompatibility due to the spread of a self-fertility allele. We shall consider this in section 3 below.

\section{Spread of a NEW $S$ allele}

The population is assumed to be initially homogeneous for an $S_{f}$ allele. We imagine that a new allele at the same locus arises by mutation and behaves as an active $S$ allele, in other words plants carrying the new allele,

TABLE 1

Genotypes produced (and their frequencies) in a population homogeneous for $\mathrm{S}_{\mathrm{f}}$, but with one active $\mathrm{S}$ allele

$\underbrace{\text { Penotypes }}_{\begin{array}{c}\text { Genotype of } \\ \text { P parent }\end{array}} \overbrace{\overbrace{\text { Contribution of progeny }}^{\text {Progeny of selfing }}}^{\overbrace{S_{f} \text { pollen }}^{\text {Progeny of outcrossing }}}$

$\begin{array}{ccccccc}S_{f} S_{f} & s(1-\delta) & S_{f} S_{f} & (1-s)\left(1-\frac{x}{2}\right) & S_{f} S_{f} & (1-s) \frac{x}{2} & S_{f} S_{1} \\ S_{f} S_{1} & s^{\prime}(1-\delta) & \begin{array}{c}\frac{1}{2} S_{f} S_{f} \\ \frac{1}{2} S_{f} S_{1}\end{array} & 1-s^{\prime} & \frac{1}{2} S_{f} S_{f} & 0 & - \\ \frac{1}{2} S_{f} S_{1} & & \end{array}$


$S_{1}$ say, inhibit pollen carrying $S_{1}$. With just these two alleles in the population, there are only two genotypes, $S_{f} S_{f}$ and $S_{f} S_{1} ; S_{f} S_{1}$ cannot arise if the incompatibility reaction is complete. Let the selfing rate of $S_{f} S_{f}$ plants be $s$. $S_{f} S_{1}$ plants can also self-fertilise, but only $S_{f}$ pollen is effective, so that the progeny will be half $S_{f} S_{f}$ and half $S_{f} S_{1}$. It seems reasonable to assume that, since only half the pollen of this genotype is compatible in self-pollinations, its selfing rate will be somewhat lower than $s$. We shall write $s^{\prime}$ for this selfing rate. Table 1 shows the genotypic outputs with this model. If the frequency of $S_{f} S_{1}$ in one generation is $x$, it is simple to work out that the frequency in the next generation, $x^{\prime}$ is:

$$
(1-s)(1-x) \frac{x}{2}+\frac{x}{2}\left\{s^{\prime}(1-\delta)+1-s^{\prime}\right\} /\left\{1-s \delta+x \delta\left(s-s^{\prime}\right)\right\}
$$

where $\delta$ measures the reduction in the chance of giving rise to a progeny that survives to the next generation, for an ovule that is fertilised by selfpollen, relative to the chance for a non-selfed ovule (see Charlesworth and Charlesworth, 1978b). This assumes that all genotypes have the same number of ovules available for fertilisation. Thus $\delta$ includes two distinct factors. The first is the reduction of viability due to selfing (i.e. inbreeding depression), and the second is the chance that an ovule that is not selfed may remain unfertilised. In the case of a rare, active $S$ allele spreading in a population of $S_{f} S_{f}$ plants, virtually all pollen received by $S_{f} S_{1}$ is compatible, so we can neglect the second factor, and consider $\delta$ as simply a measure of inbreeding depression.

When $S_{1}$ is rare, equation (1) leads to the result:

$$
\frac{x^{\prime}}{x} \approx\left(2-s-s^{\prime} \delta\right) / 2(1-s \delta)
$$

For $S_{1}$ to increase from a low frequency, we must therefore have

$$
s^{\prime}<s(2 \delta-1) / \delta
$$

This shows that $\delta>\frac{1}{2}$ is a necessary condition, though considerably higher values of $\delta$ are required if the presence of $S_{1}$ does not reduce selfing very greatly. For example, if $s^{\prime}=s / 2$, an unrealistically large drop in the selfing rate, the new allele will not spread unless $\delta>2 / 3$.

Equation (1) also gives an expression for the equilibrium frequency of the genotype carrying the new $S$ allele:

$$
\hat{x}=\frac{s(2 \delta-1)-s^{\prime} \delta}{s(2 \delta-1)-2 s^{\prime} \delta}+1
$$

For example, with $s=0.7, s^{\prime}=0.4$ and $\delta=0.8$, the new $S$ allele can enter the population, and spreads to an equilibrium frequency of about 0.064 , assuming that $\partial$ does not change during the spread of the gene.

The case of imperfect incompatibility reactions can also be dealt with. The analogue of table 1 is more complicated, since the genotype $S_{1} S_{1}$ is possible when $S_{1}$ pollen is not completely excluded from pollinating plants carrying $S_{1}$. However, it is reasonable to assume that though $S_{f} S_{1}$ plants can self-fertilise, the $S_{f}$ pollen is responsible for all such selfed progeny, so that $S_{1} S_{1}$ would not be produced by selfing of $S_{f} S_{1}$. If this is the case, and if $S_{1}$ is rare, $S_{1} S_{1}$ progeny are produced only by outcrossing of $S_{1}$ pollen 
In all cases we find that this does not occur, but a polymorphism is established, with $S_{f}$ and $S_{1}, S_{2}$ and $S_{3}$ all present. At such an equilibrium, all active $S$ alleles are present at the same frequency, since they all have identical properties (except for the specificity of their reactions). Table 2 shows some examples, demonstrating that, far from being eliminated, $S_{f}$ is

TABLe 2

Frequencies of active $\mathrm{S}$ alleles in populations also segregating for $\mathrm{S}_{\mathrm{P}}$ ( (- indicates that this run was not done)

\begin{tabular}{|c|c|c|c|c|c|}
\hline \multicolumn{2}{|c|}{ Selfing rates of } & \multirow{3}{*}{$\begin{array}{c}\text { Inbreeding } \\
\text { depression } \\
(\delta)\end{array}$} & \multirow{2}{*}{\multicolumn{3}{|c|}{$\begin{array}{c}\text { Equilibrium frequency of each } S \\
\text { when number of } S_{i} \text { alleles is }\end{array}$}} \\
\hline \multirow{2}{*}{$\begin{array}{c}S_{f} S_{f} \\
(s)\end{array}$} & \multirow{2}{*}{$\begin{array}{l}S_{f} S_{i} \\
\left(s^{\prime}\right)\end{array}$} & & & & \\
\hline & & & 1 & 2 & 3 \\
\hline $0 \cdot 7$ & 0.05 & $0 \cdot 8$ & $0 \cdot 141$ & $0 \cdot 123$ & $0 \cdot 110$ \\
\hline $0 \cdot 7$ & $0 \cdot 4$ & $0 \cdot 8$ & 0.064 & 0.065 & 0.066 \\
\hline $0 \cdot 7$ & 0.5 & $0 \cdot 8$ & $\sim 0.005$ & - & - \\
\hline 0.7 & 0.53 & 0.8 & 0 & - & - \\
\hline $0 \cdot 7$ & $0 \cdot 4$ & 0.95 & $0 \cdot 144$ & 0.137 & $0 \cdot 133$ \\
\hline
\end{tabular}

present at very high frequency in such populations, even when there is strong inbreeding depression. Thus, although the presence of three active $S$ alleles is a necessary condition for the evolution of a self-sterile population, it is not sufficient.

\section{INVASION OF POPULATIONS BY SELF-FERTILITY ALLELES}

In the previous section, we showed that $S_{f}$ alleles are not eliminated from populations containing three $S_{i}$ alleles. It would be interesting to know what happens if more $S_{i}$ alleles are present. This is hard to study by the methods used so far, which involve expressions for the frequencies of every genotype, but this is not necessary. If all the $S_{i}$ alleles have the same frequency, one can write equations for the frequencies of genotypes of each class after one generation of mating, without distinguishing all the particular individual genotypes. We have done this for populations with $n$ active alleles and either an $S_{f}, S_{1^{\prime}}$ or an $S_{1^{\prime \prime}}$ allele.

\section{(i) $\mathrm{S}_{f}$ allele and $\mathrm{n} \mathrm{S}_{i}$ alleles}

Let the frequency of $S_{f} S_{f}$ be $x_{1}$. Let that of $S_{f} S_{i}$ be $x_{2}$; there are $n$ different possible genotypes of this sort, so the total frequency of $S_{f}$ heterozygotes is $n x_{2}$. Let the frequency of $S_{i} S_{j}$ be $x_{3}$; there are $n(n-1) / 2$ such genotypes. Finally let the frequency of each $S_{i}$ allele be $p$; the frequency, $p_{f}$, of $S_{f}$ is $\frac{n x_{2}}{2}+x_{1}=1-n p \quad$ With this notation, the equations for the frequencies in next the generation are:

$$
\begin{aligned}
& x_{1}^{\prime} W=x_{1}\left\{s(1-\delta)+(1-s) p_{f}\right\}+\frac{n x_{2}}{2}\left\{s^{\prime}(1-\delta)+\left(1-s^{\prime}\right) \frac{p_{f}}{1-p}\right\} \\
& x_{2}^{\prime} W=x_{1}(1-s) p+\frac{x_{2}}{2}\left\{s^{\prime}(1-\delta)+\frac{\left(1-s^{\prime}\right)}{1-p}\left[(n-1) p+p_{f}\right]\right\}+\frac{x_{3}(n-1) p_{f}}{2(1-2 p)}
\end{aligned}
$$


where $W$ is a normalising factor. If we assume that all plants receive enough pollen to fertilise all their ovules, the value of $W$ is

$$
1-x_{1} s \delta-x_{2} s^{\prime} \delta
$$

These equations can be used to calculate equilibrium frequencies in populations, but they also can be used to study the case when $S_{f}$ is rare, i.e. to study the spread of an $S_{f}$ mutation in a self-incompatible population. When $S_{f}$ is absent, we have

$$
p \approx \frac{1}{n} \text { and } W=1 .
$$

Neglecting terms of order 2 in the frequency of $S_{f}$, we obtain:

$$
\begin{aligned}
& x_{1}^{\prime} \approx x_{1} s(1-\delta)+n x_{2} s^{\prime} \frac{(1-\delta)}{2} \\
& n x_{2}^{\prime} \approx x_{1}\left(1-s+\frac{n}{n-2}\right) \frac{n x_{2}}{2}\left(1-s^{\prime} \delta+\frac{n}{n-2}\right)
\end{aligned}
$$

These equations can be used to solve two different problems. First, assuming large $n$, what is the minimum value of $\delta$ that will prevent $S_{f}$ from spreading? Second, is there some number of alleles which makes it impossible to maintain $S_{f}$ in the population?

The first question can be solved by noting that when $n$ is very large 4(b) becomes

$$
n x_{2}^{\prime} \approx x_{1}(2-s)+n x_{2}\left(1-\frac{1}{2} s^{\prime} \delta\right)
$$

The characteristic equation for this case is

$$
f(\lambda)=\lambda^{2}-\lambda\left[1+s-\delta\left(s+\frac{1}{2} s^{\prime}\right)\right]+(1-\delta)\left(s-s^{\prime}\right)+s s^{\prime}\left[\frac{1}{2}\left(1+\delta^{2}\right)-\delta\right]
$$

This can be solved to yield the value of $\delta$ which makes $f(1)=0$. This gives the critical value of $\delta$, which may not be exceeded if $S_{f}$ is to spread:

$$
\begin{aligned}
& \delta_{c}^{2} \times \frac{1}{2} s+\delta_{c}\left(\frac{3}{2}-s\right)-\left(1-\frac{1}{2} s\right)=0 \\
& \delta_{c}=\left(s-\frac{3}{2}+\sqrt{\frac{9}{4}-s}\right) / s
\end{aligned}
$$

Table 3 shows values of $\delta_{c}$. Equation (5) shows that as $s \rightarrow 0, \delta_{c} \rightarrow \frac{2}{3}$, and table 3 shows that $\delta_{c}$ is not much lower, even with very high selfing rates. With smaller numbers of alleles, the critical value of $\delta$ is increased, in other words, it is easier for the self-fertility allele to spread.

This result suggests that there might be some value of $n$ which prevents the spread of $S_{f}$, even though the other parameters have values that permit $S_{f}$ to be present when $n$ is smaller. The case of $\delta=1$ can be solved analytically; this is the case which makes $S_{j}$ most likely to be eliminated. For this case, equations (4) have a particularly simple characteristic equation. One eigenvalue is zero, and the other is given by

$$
\lambda_{0}=\frac{1}{2}\left(1+\frac{n}{n-2}-s^{\prime}\right)
$$

The condition for $S_{f}$ to spread $\left(\left(\lambda_{0}>1\right)\right.$ is thus

$$
n>2\left(1+s^{\prime}\right) / s^{\prime}
$$




\section{TABLE 3}

Minimum value of the inbreeding depression parameter $\delta$ that prevents an $\mathrm{S}_{\mathfrak{f}}$ allele from spreading in a population with a very large number of active $\mathbf{S}$ alleles

$\begin{array}{lc}s & \text { Critical value of } \delta \\ 1.0 & 0.610 \\ 0.8 & 0 \cdot 630 \\ 0.6 & 0.641 \\ 0.4 & 0.650 \\ 0 \cdot 2 & 0.659 \\ 0 & 0.667\end{array}$

Table 4 shows some values of the minimum value of $n$ that prevents the spread of $S_{y}$. As might be expected, the number is strongly affected by the value of $\delta$, so some examples of the results of computer calculations with various $\delta$ values are also given in table 4. Large numbers of alleles are often compatible with the retention of $S_{f}$ in the population. With $\delta=1$, (6) shows that the critical value of $n$ is always above 4, with higher numbers if $\delta<1$.

Some equilibrium frequencies of $S_{f}$ with various parameter values are given in table 5 .

\section{TABLE 4}

Minimum numbers of alleles that prevent the spread of $\mathrm{S}_{\mathrm{f}}$ alleles. (- indicates that this case was not studied)

\begin{tabular}{cccc}
\multicolumn{4}{c}{ Critical value of $n\left\langle n_{c}\right\rangle$} \\
$n_{s^{\prime}} \delta=1.0$ & $\delta=0.9$ & $\delta=0.7$ \\
1.0 & 5 & - & - \\
0.8 & 5 & - & - \\
0.6 & 6 & - & - \\
0.4 & 8 & - & - \\
0.2 & 12 & - & - \\
0.1 & 23 & $25<n_{c}<30$ & $n_{c} \approx 101$
\end{tabular}

TABLE 5

Equilibrium frequencies of various genotypes obtained by computer calculation of the full set of equations for a population containing $\mathrm{S}_{\mathrm{P}}$ and $\mathrm{n}$ different $\mathrm{S}_{\mathrm{1}}$ alleles. The value of $\mathrm{s}$ was 0.7 throughout

\begin{tabular}{cccccc}
$\begin{array}{c}\text { Selfing rate } \\
\text { of } S_{f} S_{i} \\
\left(s^{\prime}\right)\end{array}$ & $\delta$ & $\begin{array}{c}\text { Number of } \\
\text { alleles }\end{array}$ & \multicolumn{3}{c}{ Aggregate genotype frequencies } \\
0.6 & 0.9 & 4 & $S_{f} S_{s}$ & All $S_{f} S_{i}$ & All $S_{i} S_{j}$ \\
0.6 & 0.9 & 6 & 0.336 & 0.525 & $0 \cdot 139$ \\
0.4 & 0.9 & 4 & 0.020 & 0.238 & 0.742 \\
0.4 & 0.9 & 6 & 0.281 & 0.538 & 0.181 \\
0.6 & 0.7 & 15 & 0.099 & 0.458 & 0.443 \\
0.6 & 0.7 & 20 & 1.000 & 0 & 0 \\
0.4 & 0.7 & 15 & 1.000 & 0 & 0 \\
0.4 & 0.7 & 20 & 0.000 & 0 & 0 \\
& & & 0.625 & 0.326 & 0.049
\end{tabular}


(ii) $\mathrm{S}_{1^{\prime}}$ allele (inactive in pollen) and $\mathrm{n}_{i}$ alleles

The spread of a mutation to an $S$ allele with no pollen activity can be studied in a similar way, but is somewhat more complicated if the mutant allele has the same stylar specificity as one of the active $S$ alleles, $S_{1}$ say. If this is so, we must take account of the frequencies of those genotypes containing $S_{1}$ separately from those of other $S_{i}$ alleles. Table 6 shows the

TABLE 6

Genotypes in a population with $\mathrm{n}$ different $\mathrm{S}_{\mathrm{i}}$ alleles and a mutant $\mathrm{S}_{1}{ }^{\prime}$ allele with no pollen activity, but with the specificity of $\mathrm{S}_{1}$ in the style

$\begin{array}{lccc}\text { Genotype } & \begin{array}{c}\text { Frequency of } \\ \text { individual } \\ \text { genotype }\end{array} & \begin{array}{c}\text { Number of } \\ \text { genotypes }\end{array} & \text { Selfing rate } \\ S_{1} S_{1^{\prime}} & x_{1} & 1 & s \\ S_{1} S_{1} & x_{2} & 1 & s^{\prime} \\ S_{1} S_{i}(i>1) & x_{3} & n-1 & s^{\prime} \\ S_{1} S_{i}(i>1) & x_{4} & n-1 & 0 \\ S_{i} S_{j}(i, j>1) & x_{5} & \frac{(n-1)(n-2)}{2} & 0\end{array}$

genotypic classes, their selfing rates, and the notation used in what follows. Writing $p^{\prime}$ for the frequency of $S_{1^{\prime}}$ in pollen, and $p_{1}$ for the frequency of $S_{1}$, the equations for the new genotype frequencies $x_{1}^{\prime}-x_{5}^{\prime}$ after one generation are

$$
\begin{aligned}
& x_{1}^{\prime} W=x_{1}\left[s(1-\delta)+(1-s) \frac{p^{\prime}}{1-p_{1}}+\frac{x_{2}}{2} s^{\prime}(1-\delta)+\left(1-s^{\prime}\right) \frac{p^{\prime}}{1-p_{1}}\right] \\
& \quad+\frac{x_{3}}{2}(n-1)\left[s^{\prime}(1-\delta)+\frac{\left(1-s^{\prime}\right) p^{\prime}}{1-p_{1}-p}\right] \\
& x_{2}^{\prime} W=\frac{x_{2}}{2}\left[s^{\prime}(1-\delta)+\frac{\left.\left(1-s^{\prime}\right) p^{\prime}\right]}{1-p_{1}}\right]+\frac{x_{4}(n-1) p^{\prime}}{2\left(1-p_{1}-p\right)} \\
& x_{3}^{\prime} W=x_{1}(1-s) \frac{p}{1-p_{1}}+\frac{x_{2}\left(1-s^{\prime}\right) p}{2\left(1-p_{1}\right)} \\
& \quad+\frac{x_{3}\left[s^{\prime}(1-\delta)+\frac{\left(1-s^{\prime}\right)}{1-p_{1}-p}\left(p^{\prime}+\{n-2\} p\right)\right]}{2\left(1-p_{1}-p\right)}+\frac{x_{5}(n-2) p^{\prime}}{2(1-2 p)} \\
& x_{4}^{\prime} W=\frac{x_{2}\left(1-s^{\prime}\right) p}{2\left(1-p_{1}\right)}+\frac{x_{4}(n-2) p}{2\left(1-p_{1}-p\right)}+\frac{x_{5}(n-2) p}{2(1-2 p)} \\
& x_{5}^{\prime} W=\frac{x_{3}\left(1-s^{\prime}\right) p}{1-p_{1}-p}+\frac{x_{4} p}{1-p_{1}-p}+\frac{x_{5}(n-3) p}{1-2 p}
\end{aligned}
$$

where $W$ is a normalising factor. As before, when $n$ is large this set of equations can be used to solve for the minimum value of $\delta$ that prevents $S_{1}$, from spreading; this turns out to be exactly the same as for the previous 
case. The minimum number of $S_{i}$ alleles that produce a system which eliminates a mutant $S_{1}$, when $\delta=1$ can also be found. The values are similar to those in table 4 , different by at most 1 in a few cases. One might expect that the presence of $S_{1}$ would make the spread of $S_{1}$ less easy than that of $S_{f}$; in the present context, we therefore expect that the critical number of active $S$ alleles would be lower than that required to cause elimination of $S_{f}$, and this is indeed observed.

Some calculated equilibrium frequencies of the genotypes in this model are shown in table 7 . The frequencies of $S_{1^{\prime}} S_{1^{\prime}}$ are higher than those of

TABLE 7

Equilibrium frequencies in populations with $\mathrm{n}$ active $\mathrm{S}$ alleles, and a mutant $\mathrm{S}_{\mathbf{1}}{ }^{\prime}$ allele with no activity in pollen and $\mathrm{S}_{2}$ siylar specificity. The value of $\mathrm{s}$ was 0.7

\begin{tabular}{|c|c|c|c|c|c|c|c|}
\hline \multirow{2}{*}{$\begin{array}{l}\text { Selfing } \\
\text { rate of } \\
S_{1}^{\prime} S_{i} \\
\left(s^{\prime}\right)\end{array}$} & \multicolumn{3}{|c|}{$\begin{array}{l}\text { Number } \\
\text { of active } \\
\text { alleles } \\
\text { (including }\end{array}$} & & \multicolumn{3}{|c|}{ Genotype frequencies } \\
\hline & $\delta$ & $\begin{array}{c}\left.S_{1}\right) \\
(n)\end{array}$ & $S_{1}^{\prime} S_{1}^{\prime}$ & $S_{1} S_{1}$ & $\begin{array}{c}\text { All } S_{1} S_{i} \\
(i \neq 1)\end{array}$ & $\begin{array}{c}\text { All } S_{1} S_{i} \\
(i \neq 1)\end{array}$ & $\begin{array}{c}\text { All } S_{i} S_{j} \\
(i, j \neq 1)\end{array}$ \\
\hline $0 \cdot 6$ & 0.9 & 4 & $0 \cdot 656$ & 0 & 0.320 & 0 & $0 \cdot 024$ \\
\hline $0 \cdot 6$ & 0.9 & 6 & 0.055 & $0 \cdot 026$ & 0.347 & $0 \cdot 118$ & 0.455 \\
\hline 0.4 & 0.9 & 4 & 0.410 & 0 & 0.497 & 0 & $0 \cdot 092$ \\
\hline $0 \cdot 4$ & 0.9 & 6 & $0 \cdot 177$ & 0 & 0.524 & 0 & 0.299 \\
\hline $0 \cdot 6$ & 0.7 & 15 & $1 \cdot 000$ & 0 & 0 & 0 & 0 \\
\hline $0 \cdot 6$ & 0.7 & 20 & $1 \cdot 000$ & 0 & 0 & 0 & 0 \\
\hline 0.4 & 0.7 & 15 & 1.000 & 0 & 0 & 0 & 0 \\
\hline $0 \cdot 4$ & 0.7 & 20 & $>0.71$ & 0 & $<0.27$ & 0 & $<0.03$ \\
\hline
\end{tabular}

$S_{f} S_{f}$ at equilibrium, because $S_{1}$ is usually eliminated (in one case it is merely depressed in frequency compared with the other $S_{i}$ alleles); the $S_{1^{\prime}}$ allele is therefore at equilibrium not with $n$, but with $n-1$ other alleles.

(iii) $\mathrm{S}_{\mathbf{1}^{\prime \prime}}$ allele (inactive in the style) and $\mathrm{n}_{\mathrm{i}}$ alleles

This case can be studied in the same way as the $S_{1}$ allele. A table like table 6 can be drawn up; the only difference is that $S_{1^{\prime \prime}} S_{1}$ cannot selffertilise. The equations for the genotypes are (using analogous notation to the previous case):

$$
\begin{aligned}
& x_{1}^{\prime} W=x_{1}\left[s(1-\delta)+(1-s) p^{\prime \prime}\right]+\frac{x_{2}(n-1)}{2}\left[s^{\prime}(1-\delta)+\frac{\left(1-s^{\prime}\right) p^{\prime \prime}}{1-p}\right] \\
& x_{2}^{\prime} W=x_{1}(1-s) p_{1}+\frac{x_{3}(n-1)\left(1-s^{\prime}\right) p_{1}}{2(1-p)} \\
& x_{3}^{\prime} W=x_{1}(1-s) p+\frac{x_{2} p}{2\left(1-p_{1}-p^{\prime \prime}\right)} \\
& \quad+\frac{x_{3}}{2}\left[s^{\prime}(1-\delta)+\frac{\left(1-s^{\prime}\right)}{1-p}\left\{p^{\prime \prime}+(n-2) p\right\}\right] \\
& +\frac{x_{5}(n-2) p^{\prime \prime}}{2(1-2 p)}
\end{aligned}
$$




$$
\begin{aligned}
x_{4}^{\prime} W & =\frac{x_{2} p}{2\left(1-p_{1}-p^{\prime \prime}\right)}+\frac{x_{3}\left(1-s^{\prime}\right) p_{1}}{2(1-p)}+\frac{x_{4}(n-2) p}{2\left(1-p_{1}-p^{\prime \prime}-p\right)}+\frac{x_{5}(n-2) p_{1}}{2(1-2 p)} \\
x_{5}^{\prime} W & =\frac{x_{3}\left(1-s^{\prime}\right) p}{1-p}+\frac{x_{4} p}{1-p_{1}-p-p^{\prime \prime}}+\frac{x_{5}(n-3) p}{1-2 p}
\end{aligned}
$$

Again, when $n$ is very large, the critical value of $\delta$ is $\frac{2}{3}$. Following the same procedure as before for the case of $\delta=1$, when $S_{1^{\prime \prime}}$ is rare, the leading eigenvalue is given by the equation

$$
\lambda_{0}=1-\frac{1}{2} s^{\prime}-\frac{\left(1-s^{\prime}\right)}{2(n-1)}
$$

This shows that $\lambda_{0}$ is always less than 1 (since $n$ must be greater than 1 ). There is therefore no critical value of $n$ that makes the population immune to the spread of $S_{1^{\prime \prime}}$ : if $\delta$ is less than some critical value, $S_{1^{\prime \prime}}$ will always be able to spread, whatever the number of alleles. Table 8 shows some equilibrium populations. The results are not much affected by the value of $n$, but depend chiefly on $\delta$. When $\delta$ is low enough to permit $S_{1^{\prime \prime}}$ to spread, it generally rises to a high frequency, and is often fixed.

\section{TABLE 8}

\begin{tabular}{|c|c|c|c|c|c|c|c|}
\hline \multirow{2}{*}{$\begin{array}{l}\text { Selfing } \\
\text { rate of } \\
S_{1^{\prime \prime \prime}} S_{1^{\prime \prime}} \\
(s)\end{array}$} & \multicolumn{3}{|c|}{$\begin{array}{l}\text { Number } \\
\text { of active } \\
\text { alleles } \\
\text { (including }\end{array}$} & & \multicolumn{3}{|c|}{ Genotype frequencies } \\
\hline & $\delta$ & $\begin{array}{c}\text { (including } \\
\left.S_{1}\right) \\
(n)\end{array}$ & $S_{1^{\prime \prime \prime}} S_{1^{\prime \prime}}$ & $S_{1} S_{1^{\prime \prime}}$ & $\underset{(i \neq 1)}{\operatorname{All} S_{1 \prime \prime} S_{i}}$ & $\begin{array}{l}\text { All } S_{1} S_{i} \\
(i \neq 1)\end{array}$ & $\begin{array}{r}\text { All } S_{i} S_{j} \\
(i, j \neq 1)\end{array}$ \\
\hline \multirow[t]{4}{*}{9} & 0.55 & 6 & $0 \cdot 353$ & 0.009 & $0 \cdot 363$ & 0.092 & $0 \cdot 182$ \\
\hline & & 20 & $0 \cdot 360$ & 0.006 & 0.371 & 0.059 & $0 \cdot 205$ \\
\hline & $0 \cdot 4$ & 6 & $1 \cdot 000$ & 0 & 0 & 0 & 0 \\
\hline & & 20 & $1 \cdot 000$ & 0 & 0 & 0 & 0 \\
\hline \multirow[t]{4}{*}{$0 \cdot 6$} & 0.55 & 6 & 0.499 & 0.014 & $0 \cdot 342$ & $0 \cdot 056$ & $0 \cdot 089$ \\
\hline & & 20 & $0 \cdot 504$ & 0.010 & $0 \cdot 346$ & $0 \cdot 044$ & 0.097 \\
\hline & $0 \cdot 4$ & 6 & $1 \cdot 000$ & 0 & 0 & 0 & 0 \\
\hline & & 20 & $1 \cdot 000$ & 0 & 0 & 0 & 0 \\
\hline
\end{tabular}

Equilibrium genotype frequencies in populations containing $\mathrm{n} \mathrm{S}_{\mathrm{i}}$ alleles and a mutant allele $\mathrm{S}_{1 \text { " with no }}$ stylar activity, but $\mathrm{S}_{1}$ pollen specificity. The value of $\mathrm{s}^{\prime}$ was 0.5

\section{Discussion}

Assuming for the moment that mutations can occur between the different forms of $S$ allele (active, inactive in pollen, inactive in the styles), the results presented above show that not until considerably more than three active alleles are present can the original allele (whether $S_{f}, S_{\mathbf{1}^{\prime}}$ or $S_{\mathbf{1}^{\prime \prime}}$ ) be eliminated. On this view of the evolution of $S$ allele systems, one would therefore expect that the ancestral allele should sometimes be found segregating in species with active $S$ alleles. Such polymorphic populations could also arise by the spread of wholly inactive $\left(S_{f}\right)$ alleles, or alleles with inactivity of the pollen $\left(S_{1^{\prime}}\right)$ or stylar $\left(S_{1^{\prime \prime}}\right)$ reaction, into self-incompatible species. For self-incompatibility to be stable to the introduction of such alleles, the results of section 4 show that the inbreeding depression $(\delta)$ 
must exceed some critical value, which in the case of $S_{f}$ and $S_{1}$ alleles decreases with the number of active alleles, but is generally very high (around $2 / 3$, see table 3 ). In the case of alleles with no reaction in the stigma $\left(S_{f}\right.$ and $S_{1^{\prime \prime}}$ ), plants carrying these alleles show incompatibility towards fewer pollen types than normal $S$ heterozygotes, and this must increase the chance of fertilisation for their non-selfed ovules, compared with that of the ovules of $S_{i} S_{j}$ plants. This suggests that if pollen transfer becomes limiting, due to a decline in insect visits, the advantage of such alleles would be greater than the equations of sections 4 (i) and (iii) would predict. Even without taking this into account tables 5, 7 and 8 show that self-fertility alleles often rise to high frequencies, or are even fixed, if they are able to spread at all. Polymorphism for such alleles is generally obtained only within a narrow range of parameter values, and would therefore be unlikely to be commonly found (except as a transient stage while such alleles are spreading; this stage may be of the order of hundreds of generations when there are many active alleles).

There is considerable evidence for the presence of $S_{f}$ alleles in selfcompatible species with known incompatible relatives, such as $\mathcal{N}$. langsdorffi (East, 1919, 1929, 1932). There is less clear evidence on the occurrence of polymorphism for active and inactive $S$ alleles within species, partly because few suitable studies have been done. $S_{f}$ alleles have been found in a few species that have active $S$ alleles, and that have been very thoroughly studied, e.g. Trifolium repens (Attwood, 1942, 1945), T. hybridium (Townsend, 1965), Petunia hybrida (Takehashi, 1973). The not infrequent observation that self-fertility can be selected for may sometimes be due to the presence of $S_{f}$ alleles, and so perhaps may the occurrence of selfcompatible races in incompatible species, e.g. Nicotiana glauca (Pandey, 1969), though the genetics of this case is not known. Of course, one cannot distinguish whether self-fertility due to an allele at the $S$ locus is caused by an $S_{f}$ allele, or by one of the two other possible types studied above; to be certain that one is not dealing with $S_{j}$, one must find an active allele that inhibits pollen carrying the self-fertility allele, or one that is inhibited on the stigma of a plant carrying it. Tables 7 and 8 show that when $S_{1}$, or $S_{1^{\prime \prime}}$ allele spreads in a population, the allele with the same reaction $\left(S_{1}\right)$ is eliminated or depressed in frequency. It is thus unlikely that such reactions could be detected within one species, though perhaps where two species initially have a set of homologous active $S$ alleles, but one has become self-compatible, such relations could be discovered by inter-species pollination. The $S_{F}$ allele found in some plants of Nicotiana alata, which inhibits $\mathcal{N}$. langsdorffi pollen $\left(S_{f}\right)$ might be such a case (Anderson and De Winton, 1931). Lundqvist (1963) interprets $S_{f}$ as an allele with pollen activity, but no reaction in the style (i.e. $S_{1^{\prime \prime}}$ ), and $S_{F}$ as the allele with the same reaction (i.e. $S_{1}$ ). However, Pandey (1964) reports findings that do not fit this interpretation: two specificities of $S_{F}$ were found, and also the inhibition of $S_{f}$ on $S_{F}$ plants occurred in the stigma, not in the style, as is the case for normal interactions in $\mathcal{N}$. alata.

It should also be recalled that self-compatibility can be due to causes other than $S$ gene mutations. Apart from polyploidy (Crane and Lawrence, 1929; Crane and Lewis, 1942) and trisomy for the $S$ locus (Brewbaker and Natarajan, 1960; Pandey, 1965), the strength of the incompatibility reaction can be affected by a number of modifier loci (e.g. Brieger, 1927; 
Anderson and De Winton, 1931; Townsend, 1971; Takehashi, 1973); "pseudo-compatibility" is frequently found. Such effects could, for example, be due to changes in the time of expression of the $S$ genes, as it is known that in the bud stage many species are compatible (East, 1929; see also East and Yarnell, 1929), and that this is due to the absence from immature flowers of the incompatibility substance (Nasrallah and Wallace, 1967; Nasrallah, 1974; Nishio and Hinata, 1977). It is easy to show that pseudo-compatibility due to modifier loci would be advantageous whenever $\delta<\frac{1}{2}$ (assuming a dominant mutation at such a locus abolishing the stylar incompatibility reaction).

Returning to the evolution of $S$-allele systems, the chief problem with the model studied in sections 2 and 3 is the assumption that the mutation from a self-fertility allele $\left(S_{f}\right.$, say) to an active $S$ allele is possible. Since we know nothing about the ancestral conditions of the $S$ gene product (or, indeed, its present biochemical properties), we cannot say whether such a mutation is plausible or not. Of course, this model is only one possibility for the evolution of $S$-allele systems. There appear to be two basic classes of possible models. The first includes such models as the one studied above, in which specificities leading to incompatibility arise by mutation from an ancestral allele without such specificities. Such a change is hard to imagine, but the reverse change can occur from an active S-allele to one with no pollen reaction yet which still produces a generally homologous product. The proof of this comes from Lewis's (1960) study of mutants with no activity in pollen, but which in diploid pollen can complement with certain active $S$ alleles, so that specificity is restored. These mutant alleles have also been shown to produce $S$ gene product (Mäkinen and Lewis, 1962).

An alternative type of model for the evolution of $S$-allele systems assumes that a variety of (allelic) specificities is initially present without causing an incompatibility reaction, and that selection acts on loci (other than the $S$ locus) which affect the chance that pollen which matches an allele in the stigma-bearing plant will be rejected. This model, with polygenic control of the strength of the reactions, was proposed by Mather (1943). It has been documented in several species that more than one modifier locus may affect the strength of self-compatibility (see above). There is, however, no evidence for polygenic control of specificity, as proposed by Bateman (1952). The multi-locus incompatibility systems found in grasses and some other families (see Lundqvist, 1975) seem most likely to have evolved by this second route, since it is hard to believe in the occurrence of suitable mutations at two or more loci at the start of the evolution of the incompatibility system.

Many of the problems in trying to understand how $S$-allele systems can evolve would become easier if the biochemical nature of the product of these alleles were known. This is, of course, receiving considerable attention from a number of workers, though most work is done on the sporophytic incompatibility system in Brassica, rather than on gametophytic systems, which may have different properties. The very large number of alleles possible at this locus (East and Yarnell, 1929; Emerson, 1939; Williams, 1951) suggests that the specificity substance is a protein, and this is supported by the occurrence of complementation between alleles (Lewis, 1960). There is direct evidence in Brassica, in which the stigma specificity substance stains as a glycoprotein (Nishio and Hinata, 1977), and in Oenothera 
organensis, in which the pollen specificity substance is probably a protein (Mäkinen and Lewis, 1962). Although it seems most likely that the pollen and stylar substances are identical (Lewis, 1960, 1963), no direct proof of this has yet been obtained; antisera which detect specific pollen substances have so far proved unable to detect stigma substances, and vice versa (Nasrallah and Wallace, 1967; Clarke et al., 1977).

If the substance responsible for the incompatibility reaction is a protein, with multiple antigenic sites, a possible explanation suggests itself for the non-occurrence of mutations from one active $S$ allele to another (Lewis, $1948,1949,1951)$. The test for mutations consists of screening selfincompatible plants for progeny after self-fertilisation. Such progeny can result from fertilisation by pollen carrying mutations either to polleninactive alleles, or to alleles different from those in the parent plant. Only the former type was found in Lewis's experiments. Fisher (1961) pointed out that this might be expected if new alleles arose by crossing-over between two alleles, each carrying a different antigenic specificity. The new allele would carry specificities of both parental alleles, and would thus be incompatible on the parent plant. The same argument could apply to any new allele that arose by mutation: if such an allele simply acquired a new specificity, without loss of the original one(s), it would be incompatible with the plant in which it arose. This leads to the prediction that a new allele will be most likely to spread if it carries a new specificity, but not any pre-existing specificity. Thus a whole range of alleles could conceivably arise from an ancestral allele without specificities that lead to incompatibility reactions $\left(S_{f}\right)$. The results of section 4 above show that an $S_{f}$ allele can remain in a population even when a large number of active $S$ alleles is present.

Lewis (1962) disputed Fisher's cross-over model for the generation of new $S$ alleles, on the grounds that alleles with the properties of Fisher's recombinant alleles are not found, whereas in Fisher's model they will spread (to a lower frequency than the monospecific alleles). However, Fisher assumed that incompatibility results only when all specificities carried by a pollen grain are matched by the stigma plant. This assumption gives recombinant alleles an advantage: pollen carrying a recombinant allele is compatible with any plant carrying one or other of the alleles from which it was derived. If this were not true, recombinant alleles would be incompatible with more genotypes than monospecific alleles (Lewis, 1962, interpretation 1) and would not spread. Thus their absence in populations of self-incompatible plants does not invalidate this explanation for the lack of $S$-allele conversions.

Two tests have been done to find out whether crossing-over within the locus can generate new alleles. Lewis (1949) tested 149 progeny of a heterozygote carrying an active $S$ allele and one inactive in pollen. Crossingover should generate an allele with the specificity of the inactive allele, but active in pollen. None was found. This rules out the possibility that the $S$ locus is composed of two loci, one controlling the activity, and one the specificity, in pollen, or at least requires that they must be tightly linked. If there is really only one gene, much larger tests would be required to detect crossing-over. Lundqvist (1968) used a two-locus system to test whether self-fertility mutations can occur only at a heterozygous incompatibility locus, as would be the case if crossing-over is required, or can 
also occur at a homozygous locus. In the two-locus systems it is easy to get plants that are heterozygous at only one locus. Out of 40 alleles tested with inactive pollen reactions, 17 involved mutations at the heterozygous locus, but the remainder could either have been mutations at the homozygous locus, or at an unlinked locus. Unfortunately, these two possibilities could not be distinguished. It would be extremely interesting to know which was in fact the case in this experiment. Once again, an understanding of the nature of the incompatibility alleles and a clearer understanding of the genetics of this system, should be mutually illuminating.

\section{References}

ANDERSON, E., AND DE WINTON, D. 1931. The genetic analysis of an unusual relationship between self-sterility and self-fertility in Nicotiana. Ann. Mo. Bot. Gard., 18, 97-116.

ATTwood, s. s. 1942. Genetics of self-compatibility in Trifolium repens. 7. Amer. Soc. Agron., $34,353-364$.

ATTWOOD, s. s. 1945. The behaviour of the self-compatibility factor and its relation to breeding methods in Trifolium repens. 7. Amer. Soc. Agron., 37, 991-1004.

bateman, A. J. 1952. Self-incompatibility systems in angiosperms. I. Theory. Heredity, $6,285-310$.

вAтEMAN, A. J. 1955. Self-incompatibility systems in angiosperms. III. Cruciferae. Heredity, 9, 53-68.

BREWBAKER, J. L. 1957. Pollen cytology and incompatibility systems in plants. F. Hered., 48, 271-277.

brewbaker, J. L. 1959. Biology of the angiosperm pollen grain. Ind. F. Genet. Pl. Br., 19, 121-133.

BREWBAKER, J. L., AND NATARAjan, A. T. 1960. Centric fragments and pollen-part mutation of incompatibility alleles in Petunia. Genetics, 45, 699-704.

BRIEGer, F. 1927. Úber genetische Pseudofertilität bei der selbststerilen Nicotiana sanderae hort. Biol. Zbl., 47, 122-128.

CHARLESWORTH, B., AND CHARLESWORTH, D. 1978a. A model for the evolution of dioecy and gynodioecy. Amer. Nat., 112, 975-997.

CHARLESWORTH, D., AND CHARLESWORTH, B. 1978b. Population genetics of partial malesterility and the evolution of monoecy and dioecy. Heredity, 41, 137-153.

ClARKE, A. E., HARRISON, S., KNOX, R. B., RAFF, J., SMITh, P., AND MARCHALONIS, J. J. 1977. Common antigens and male-female recognition in plants. Nature, 265, 161-163.

CRANE, M. B., AND LEWIS, D. 1942. Genetical studies in pears. III. Incompatibility and sterility. 7. Genet., 43, 31.

CRANE, M. B., AND LAWRENCE, w. J. c. 1929. Genetical and cytological aspects of incompatibility and sterility in cultivated fruits. 7. Pomol. Hort. Sci., 7, 276-301.

CROWE, L. K. 1954. Incompatibility in Cosmos bipinnatus. Heredity, 8, 1-11.

EAST, E. M. 1919. Studies on self-sterility. III. The relation between self-fertile and selfsterile plants. Genetics, 4, 341-345.

EAST, E. M. 1929. Self-sterility. Bibl. Genet., 5, 331-337.

EAST, E. M. 1932. Studies on self-sterility. IX. The behaviour of crosses between self-sterile and self-fertile plants. Genetics, 17, 175-202.

EAST, E. M. 1940. The distribution of selffertility in the flowering plants. Proc. Amer. Philos. Soc., 82, 448-518.

EAST, E. M., AND MANGELSDORF, A. J. 1925. A new interpretation of the hereditary behavior of self-sterile plants. Proc. Natl. Acad. Sci. Wash., 11, 166-171.

EAST, E. M., AND YARNELL, S. H. 1929. Studies on self-sterility. VIII. Self-sterility alleles. Genetics, 14, 455-487.

EMERSON, s. 1939. A preliminary survey of the Oenothera organensis population. Genetics, 24, 524-537.

FISHER, R. A. 1961. A model for the generation of self-fertility alleles. F. Theoret. Biol., $1,411-414$.

Gerstel, D. U. 1950. Self-incompatibility studies in Guayule. II. Inheritance. Genetics, $35,482-506$.

hayman, D. L. 1956. The genetic control of incompatibility in Phalaris coerulescens Desf. Aust. 7. Biol. Sci., 9, 321-331. 
HESLOP-HARRISON, J., HESLOP-HARRISON, Y., AND BARBER, J. 1975. The stigma surface in incompatibility responses. Proc. Roy. Soc. Lond. B., 188, 287-298.

HUGHEs, м. B., AND BABCOCK, Е. B. 1950. Self-incompatibility in Crepis foetida L. subsp. rhoedaifolia. Genetics, 35, 570-588.

LEwIS, D. 1948. Mutation of the incompatibility gene. I. Spontaneous mutation rate. Heredity, 2, 219-236.

LEWIS, D. 1949. Mutation of the incompatibility gene. II. Induced mutation rate. Heredity, 3, 339-355.

LEWIS, D. 1951. Structure of the incompatibility gene. III. Types of spontaneous and induced mutation. Heredity, 5, 399-414.

LEWIs, D. 1960. Genetic control of specificity and activity of the $S$ antigen in plants. Proc. Roy. Soc. Lond. B., 151, 468-477.

LEWIS, D. 1962. The generation of self-incompatibility alleles. 7. Theoret. Biol., 2, 69-71. LEWIS, D. 1963. A protein dimer hypothesis on incompatibility. In Genetics Today. Proc. 11 th Int. Cong. Genet., ed. S. J. Geerts, vol. 3, pp. 657-663.

LLOYD, D. G. 1967. The genetics of self-incompatibility in Leavernworthia crassa Rollins (Cruciferae). Genetica, 38, 227-242.

LLOYD, D. G. 1975. The maintenance of gynodioecy and androdioecy in angiosperms. Genetica, 45, 325-339.

LUNDQVist, A. 1954. Studies on self-sterility in rye, Secale cereale. L. Hereditas, 40, 278-294. LundQVist, A. 1963. The genetics of incompatibility. In Genetics Today. Proc. 11 th Int. Cong. Genet., ed. S. J. Geerts, vol. 3, pp. 637-647.

LUNDQVIST, A. 1968. The mode of origin of self-fertility in grasses. Hereditas, 59, 413-426

LUNDQVIST, A. 1975. Complex self-incompatibility systems in angiosperms. Proc. Roy. Soc. Lond. B., 188, 235-245.

MÄKINEN, Y. L. A., AND LEWIS, D. 1962. Immunological analysis of incompatibility $(S)$ proteins and of cross-reacting material in a self-compatible mutant of Oenothera organensis. Genet. Res., 3, 352-363.

MATHER, K. 1943. Specific differences in Petunia. I. Incompatibility. 7. Genet., 45, 215-235.

MATHER, K. 1944. Genetical control of incompatibility in angiosperms and fungi. Nature, 153, 392-394.

NASRALlaH, м. E. 1974. Genetic control of quantitative variation in self-compatibility proteins detected by immunodiffusion. Genetics, 76, 45-50.

NASRALlah, M. E., AND WALlACE, D. H. 1967. Immunogenetics of self-incompatibility in Brassica oleracea L. Heredity, 22, 519-527.

NIshio, T., AND hiNATA, K. 1977. Analysis of $S$-specific proteins in stigma of Brassica oleracea L. by isolectric focusing. Heredity, 38, 319-396.

PANDEY, K. K. 1956. Mutations of self-incompatibility alleles in Trifolium pratense and T. repens. Genetics, 41, 327-343.

PANDEY, K. K. 1964. Elements of the S-gene complex. Genet. Res., 5, 397-409.

PANDEY, K. K. 1965. Centric chromosome fragments and pollen-part mutation of the incompatibility gene in Nicotiana alata. Nature, 206, 792-795.

PANDEy, к. K. 1969. Elements of the $S$-gene complex. IV. $S$-allele polymorphism in Nicotiana species. Heredity, 24, 601-619.

SAMPSON, D. R. 1957. The genetics of self-incompatibility in the radish. F. Hered., 48, 26-29.

SAMPSON, D. R. 1964. A one-locus self-incompatibility system in Raphanus raphanistrum. Canad. 7. Genet. Cytol., 6, 435-445.

TAKEHASHI, H. 1973. Genetical and physiological analysis of pseudo-self-incompatibility in Petunia hybrida. Jap. 7. Genet., 48, 27-33.

TOWSEND, C. E. 1965. Self-compatibility studies with diploid alsike clover, Trifolium hybridum. L. I. Frequency of self-compatible plants in diverse populations and inheritance of a self-compatibility factor $\left(S_{f}\right)$. Crop. Sci., 5, 358-360.

TOWNSEND, C. E. 1971. Further studies on the inheritance of a self-compatibility response to temperature and the segregation of $S$ alleles in diploid alsike clover. Crop. Sci., 11, 860-863.

WHITEHouse, H. L. K. 1950. Multiple-allelomorph incompatibility of pollen and style in the evolution of the angiosperms. Ann. Bot. n.s., 14, 198-216.

WILliams, R. D., AND Williams, w. 1947. Genetics of red clover (Trifolium pratense L.) compatibility. II. (a) Homozygous self-sterile $S_{x} S_{x}$ genotypes obtained as a result of pseudo-fertility; (b) Self-fertility. 7 . Genet., 48, 51-68.

williams, w. 1951. Genetics of incompatibility in alsike clover, Trifolium hybridum. Heredity, $5,51-73$. 